\title{
Z DZIEJÓW MUZYKI \\ W KOŚCIELE PW. ŚW. MIKOŁAJA W NOWYM WALISZOWIE NA ZIEMI KŁODZKIEJ
}

Nowy Waliszów (niem. Neu Waltersdorf) to nieduża wieś łańcuchowa w Kotlinie Kłodzkiej, położona na wschód od Bystrzycy Kłodzkiej w malowniczej dolinie pomiędzy Krowiarkami w Masywie Śnieżnika i Wysoczyzną Idzikowa'. Wbrew nazwie należy do najstarszych wsi w regionie. Powstała prawdopodobnie na początku XIV w. jako posiadłość rycerska. Pod koniec XVIII w. wieś należała do największych na ziemi kłodzkiej. W 1840 r. w miejscowości były aż 223 domy, kościół i szkoła, folwark, wapiennik, cztery młyny wodne, tartak, browar i gorzelnia.

Najważniejszym obiektem miejscowości jest kościół filialny pw. św. Mikołaja². Już w 1350 r. istniała w Nowym Waliszowie niewielka kaplica należąca do parafii w Starym Waliszowie ${ }^{3}$. W następnych dziesięcioleciach była rozbudowywana, a w 1389 r. przekształcono ją w kościół parafialny. Dopiero w 1520 r. wzmiankowany jest proboszcz Jacob Neugebauer, który miał żonę i był „halblutherisch”.

Dr ANDRZEJ PraSAL - adiunkt Katedry Muzykologii Uniwersytetu Opolskiego; e-mail: prasall@o2.pl

Dr ANDRZEJ Prasal - Lecturer in the Department of Musicology of the University of Opole; e-mail: prasall@o2.pl

${ }^{1}$ Por. Stownik Geografii Turystycznej Sudetów, t. 15: Kotlina Kłodzka, red. M. Staffa, Wydawnictwo I-BIS, Wrocław 1994, s. 309-314.

${ }^{2}$ Por. J. Marx, Grafschafter Kirchen in heutiger Zeit, Marx-Verlag, Leimen-Heidelberg 1978, s. 26-27; J. KöGLER, Die Chroniken der Grafschaft Glatz, t. 4: Die Chroniken der Dörfer, Pfarreien und Herrschaften des Kreises Habelschwerdt, opr. D. Pohl, Dr. Dieter Pohl Verlag, Köln 2001, s. 78-86; Kościoły i kaplice archidiecezji wrocławskiej, red. J. Pater, Kuria Metropolitalna Wrocławska, Wrocław 2002, s. 117; Kościoły Diecezji Świdnickiej. Nasze dziedzictwo, t. 3, Ikona, Bydgoszcz 2009, s. 28.

${ }^{3}$ A. Fritsch, Geschichte der Kirche zu Neuwaltersdorf. Aus älterer Zeit, „Arnestus-Blatt” 1937, nr 48, s. 681. 
W II poł. XVI w. mieszkańcy wsi przeszli na protestantyzm, co wywołało poważne zamieszki w okresie wojny trzydziestoletniej. W latach 1618-1620 wojska cesarskie siłą usunęły protestanckiego proboszcza, którego ludność wprowadziła z powrotem. W okolicy miały miejsce rozruchy na tym tle, zakończone zwycięstwem kontrreformacji i przywróceniem w 1623 r. parafii katolickiej. Ze sporządzonego w $1631 \mathrm{r}$. „Liber decanalis” dowiadujemy się, że na patrona waliszowskiej świątyni obrano św. Mikołaja, a uroczystość poświęcenia kościoła obchodzono w niedzielę po święcie Podwyższenia Krzyża św. (później w trzecią niedzielę września) ${ }^{4}$. Świątynia została powiększona i przebudowana w stylu barokowym za czasów ks. proboszcza Johanna Heinricha Schludera, w latach 1688-1724. Warto wspomnieć, że począwszy od 1730 r. zrodził się w parafii zwyczaj uroczystego obchodzenia wspomnienia św. Anny (początkowo nawet jako drugiego odpustu). W 1803 r. ukończono budowę nowej masywnej wieży kościelnej.

W 1939 r. parafię w Nowym Waliszowie, obejmującą jeszcze Białą Wodę, Czatków oraz Marcinków (z kościołem filialnym pw. św. Marcina), zamieszkiwało 1334 katolików i 18 protestantów5. W 1972 r. zniesiono parafię, przyłączając wieś do parafii w Starym Waliszowie. Obecnie miejscowość liczy nieco ponad 400 mieszkańców.

\section{ORGANY}

Pierwsze wzmianki o muzyce liturgicznej w Nowym Waliszowie związane są z organami ${ }^{6}$. Już w 1699 r. świątynia otrzymała 7 -głosowy pozytyw skonstruowany przez Johanna Junga z Lądka ${ }^{7}$. W $1745 \mathrm{r}$. instrument ten został rozbudowany o dwugłosowy pedał. W $1797 \mathrm{r}$. organy poddano gruntownej renowacji i powiększono o drugi manuał. Inwestycję sfinansowali: ks. prob. Franz Hötzel (Hetzel) oraz właściciel majątku ziemskiego i kolator kościoła baron Gisbert von Hemm und Hemmstein $^{8}$. Kolejna poważniejsza reparacja instrumentu miała miejsce w 1883 r.

\footnotetext{
${ }^{4}$ TenŻE, Geschichte der Kirche zu Neuwaltersdorf. Aus jüngerer Zeit, „Arnestus-Blatt” 1937, nr 50, s. 710.

${ }^{5}$ Verzeichnis der Pfarreien, Kuratien, Geistlichen und Ordensniederlassungen in der Grafschaft Glatz, dem preuß. Anteil der Erzdiözese Prag, Arnestus-Druckerei, Glatz 1939, s. 37.

${ }^{6}$ Por. A. Prasal, Organy w kościołach dekanatu Bystrzyca Kłodzka, Polihymnia, Lublin 2013, s. $40-43$.

${ }^{7}$ A. Fritsch, Geschichte der Kirche zu Neuwaltersdorf. Aus jüngerer Zeit, s. 710.

${ }^{8}$ Tamże, s. 710.

${ }^{9}$ Tenże, Geschichte der Kirche zu Neuwaltersdorf. Aus der letzten Jahrhundert, „Arnestus-Blatt” 1937, nr 51, s. 724.
} 
Niestety stan techniczno-muzyczny leciwych organów stale się pogarszał, stąd na początku XX w. podjęto starania o zakup nowych. W 1900 r. ks. prob. Alfred Brehl zamierzał nabyć stary instrument z kościoła parafialnego w Gorzanowie ${ }^{10}$. Były to 16-głosowe organy wybudowane w 1806 r. przez Johanna Kuttlera z Widnawy. Nie uzyskał jednak zgody rady parafialnej.

W niedzielę 7 grudnia 1902 r. miejscowe Męskie Stowarzyszenie Śpiewacze wraz z chórem parafialnym zorganizowało w gospodzie Gottschlicha koncert muzyki wokalnej i instrumentalnej, z którego dochód przeznaczono na budowę nowych organów ${ }^{11}$. W części pierwszej wykonano: marsz Grüß Gott, Wien! Karela Komzáka; uwerturę do opery La dame blanche François-Adriena Boieldieu; Chor Nr. 7 z oratorium Die Schöpfung Josepha Haydna; walc z Am Wörther See op. 26 Thomasa Koschata oraz Nachtzauber Antona Marii Storcha na chór męski. Część drugą otworzyła uwertura z opery The Bohemian Girl Michaela Williama Balfe'a. Następnie zabrzmiały: Muttersprache E.S. Engelsberga (Eduarda Schöna) na chór mieszany i alt solo oraz Maienwonne - cykl sześciu pieśni Maxa Weinzierla na chór męski. Na część trzecią złożyły się wyłącznie utwory instrumentalne, m.in.: potpourri Blüten aus der Tonwelt Hermanna Gustava Silwedela oraz marsz Rückkehr der Fahnenkompagnie von der Kaiserparade Franza von Blona. Na bis wykonano, ku radości słuchaczy, dwa utwory na ksylofon solo. Niestety zła pogoda sprawiła, że koncert nie cieszył się zbyt dużym zainteresowaniem mieszkańców.

O złym stanie waliszowskiego instrumentu dobitnie świadczy notka prasowa z 1904 r.: „31 lipca tutejsza wspólnota parafialna świętowała uroczystość św. Matki Anny. Mała świątynia wypełniona była do ostatniego miejsca. [...] Chór kościelny godnie zaprezentował wydaną dopiero przed kilkoma tygodniami mszę Paula Mittmanna. Msza stawia spore wymagania zarówno w śpiewie, jak i muzyce instrumentalnej. Szczególną uwagę należy zwrócić na w części 6-głosowe Et incarnatus est, Sanctus i Benedictus. Jako śpiewy dnia wykonano Dilexisti justitiam i Filiae regum J. Grubera oraz Introitus i Communio z Cantus. Dla odwiedzających naszą świątynię gości z zewnątrz wprost uciążliwe jest brzmienie starych organów. Zakup nowych organów byłby więc bardzo na miejscu" 12 .

Najprawdopodobniej względy finansowe nie pozwoliły na szybką realizację kosztownego przedsięwzięcia. Z tego powodu 15 marca 1909 r. członkowie Kirchenbauverein podjęli decyzję o „opodatkowaniu” każdego mieszkańca parafii

\footnotetext{
${ }^{10}$ A. Prasal, Organy w kościołach, s. 29.

${ }^{11}$ „Glatzer Zeitung” (dalej GZ) 1902, nr 97, nr 99.

12 „Der Gebirgsbote” (dalej GB) 1904, nr 63.
} 
kwotą 10 fenigów miesięcznie, m.in. na zakup organów ${ }^{13}$. Na czwartym walnym zebraniu tego stowarzyszenia 17 marca 1912 r., zarząd na czele z ks. prob. Brehlem poinformował, że nowy instrument, którego budowę traktowano jako „absolutną konieczność", został zamówiony w firmie Schlag \& Söhne ze Świdnicy ${ }^{14}$.

Montaż organów, oznaczonych jako opus 955 zakładu, ukończono latem 1912 r. Ich odbioru dokonał prof. Otto Kinkeldey $\mathrm{z}$ Wrocławia ${ }^{15}$. Zabrzmiały po raz pierwszy w niedzielę 28 lipca 1912 r. Oto relacja z tej uroczystości: „W niedzielę w kościele parafialnym uroczyście obchodzono wspomnienie św. Anny. [...] Podczas sumy chór kościelny wykonał mszę Oriens ex alto Filkego. Graduał Dilexisti był dziełem pochodzącego z hrabstwa kłodzkiego kompozytora Linnera ${ }^{16}$, a ofertorium Filiae regum - Grubera. Na wejście i komunię zaśpiewano chorał gregoriański. Po raz pierwszy zabrzmiały w pełni organy. Zostały wybudowane przez zakład organmistrzowski Schlag \& Söhne ze Świdnicy. Na dwóch manuałach i pedale rozmieszczono dziewięć realnie brzmiących głosów, które odznaczają się prawdziwym pięknem w swojej specyfice i tonie. Organy w pełni rozbrzmiewają potężnie, bez nieprzyjemnych ostrych lub krzykliwych dźwięków, a głosy górnego manuału delikatnie i przyjemnie unoszą się w świątyni. Trzy niezbędne włączniki połączeń dają grającemu możliwość wywołania w kombinacjach najrozmaitszych efektów brzmieniowych. Instrument został określony przez kompetentne osobistości jako udany" ${ }^{17}$.

W 1917 r. z instrumentu nie zarekwirowano na cele przemysłu zbrojeniowego piszczałek prospektowych, gdyż od początku wykonane były z cynku ${ }^{18}$. W lutym 1939 r. podjęto decyzję o remoncie organów oraz zainstalowaniu elektrycznej dmuchawy ${ }^{19}$. Prace powierzono firmie Berschdorf z Nysy, która w piśmie z 11 lipca 1941 r. poinformowała, że potrzebuje od czterech do sześciu miesięcy na dostarczenie tego typu urządzenia ${ }^{20}$. Zlecenie sfinalizowane zostało ostatecznie w $1942 \mathrm{r}^{21}$ Przed 1945 r. opiekę nad instrumentem sprawował także organmistrz Josef Born

${ }^{13} \mathrm{GZ} 1909$, nr 23.

${ }^{14}$ GZ 1912, nr 24.

15 „Zeitschrift für Instrumentenbau” 1912, nr 33, s. 1221.

${ }^{16}$ Josef Linner pochodził z Ruszowic k. Kłodzka.

${ }^{17}$ GB 1912, nr 62.

${ }^{18}$ Archiwum Parafii Rzymskokatolickiej pw. Wniebowzięcia NMP w Kłodzku, Das Dekanatsarchiv des Erzbischöflichen Generalvikariats der Grafschaft Glatz (dalej ADGl), b. sygn.: Orgel-Meldebogen 1943-1945.

${ }^{19}$ Pismo firmy Berschdorf z Nysy do Katolickiego Zarzadu Kościelnego w Nowym Waliszowie z 27 maja 1939 r. (zbiory własne).

${ }^{20}$ A. Prasal, Organy w kościołach, s. 42.

${ }^{21}$ Pismo firmy Berschdorf z Nysy do Katolickiego Zarzadu Kościelnego w Nowym Waliszowie z 7 lipca $1942 r$. (zbiory własne). 
z $\mathrm{Nysy}^{22}$. Po II wojnie światowej przy organach nie prowadzono poważniejszych prac restauracyjnych. Dopiero w 2018 r. ukończono generalny remont, którego wykonawcą był Sławomir Piotrowski z Modlnicy. Konserwacji prospektu dokonał Bogdan Czesak z Wieliczki.

Instrument - usytuowany centralnie na emporze wybudowanej w tylnej części świątyni - ma prospekt architektoniczny w stylu neobarokowym, ozdobiony dekoracją snycerską, malowany i złocony ${ }^{23}$. Organy posiadają 15 głosów i pneumatyczną trakturę rejestrów i gry z wiatrownicami stożkowymi. Miech magazynowy z podwójnym podawaczem o napędzie nożnym znajduje się we wnętrzu instrumentu. Powietrze dostarcza dmuchawa elektryczna umieszczona na strychu. Stół gry wbudowany jest w cokół prospektu (organista siedzi tyłem do ołtarza).

W instrumencie zastosowano tzw. system multiplex. Polega on na wykorzystaniu, przy użyciu transmisji, tego samego szeregu piszczałek do utworzenia kilku głosów, co z pewnością pozwoliło obniżyć koszt inwestycji. Z muzycznego punktu widzenia nie jest to jednak zbyt wartościowe rozwiązanie, gdyż waliszowskie organy mają jedynie dziewięć realnych głosów. Warto jednak zaznaczyć, że jest to najprawdopodobniej jedyny tego typu zachowany instrument firmy Schlag \& Söhne na ziemi kłodzkiej. Dyspozycja:

\begin{tabular}{|c|c|c|}
\hline I manual $_{\mathrm{C}-\mathrm{f}^{3}}$ & II manual & $\begin{array}{c}\text { Pedal } \\
\text { C-d }\end{array}$ \\
\hline $\begin{array}{c}\text { Bordun 16' } \\
\text { Principal 8' } \\
\text { Gambe 8' } \\
\text { Flöte 8' } \\
\text { (transmisja z Bordun) } \\
\text { Octave 4' } \\
\text { (transmisja z Principal) } \\
\text { Mixtur 2-4 fach }\end{array}$ & $\begin{array}{c}\text { Salicional 8' } \\
\text { Hohlflöte 8' } \\
\text { Aeoline 8' } \\
\text { Flöte 4' } \\
\text { (transmisja z Hohlflöte) } \\
\text { Fugara 4' } \\
\text { (transmisja z Salicional) }\end{array}$ & $\begin{array}{c}\text { Violon 16' } \\
\text { Subbass 16' } \\
\text { Bassflöte 8' } \\
\text { (transmisja z Subbass) } \\
\text { Cello 8' } \\
\text { (transmisja z Violon) }\end{array}$ \\
\hline \multicolumn{3}{|c|}{$\begin{array}{l}\text { Połączenia: Manual Koppel, Pedal Koppel I, Pedal Koppel II } \\
\text { Rejestry zbiorowe: Piano, Mezzoforte, Forte } \\
\text { Urządzenia dodatkowe: Kalikant, Windprobe }\end{array}$} \\
\hline
\end{tabular}

${ }^{22}$ ADGl, b. sygn.: Orgel-Meldebogen.

${ }^{23}$ Zob. Archiwum Wojewódzkiego Urzędu Ochrony Zabytków we Wrocławiu. Delegatura w Wałbrzychu, Karta ewidencyjna organów w kościele filialnym pw. św. Mikołaja w Nowym Waliszowie (opr. T. Grabska, J. Stępowski, 1993 r.). 


\section{CHÓR PARAFIALNY}

Parafia w Nowym Waliszowie dysponowała dość dużym zespołem wokalno-instrumentalnym. Niestety nie posiadamy bliższych informacji na jego temat. Wiadomo, że w 1930 r. liczył 31 chórzystów i 16 instrumentalistów ${ }^{24}$. Ze sporządzonego w 1939 r. inwentarza muzykaliów dowiadujemy się, że na wyposażeniu parafii były: dwa puzony, dwie skrzydłówki (flugelhornery), trzy trąbki, siedem klarnetów (w stroju C, B, A), fagot, flet, czworo skrzypiec, altówka, kontrabas, dwa kotły ${ }^{25}$.

Podobnie jak w większości miejscowości hrabstwa, waliszowskim chórem kierował główny nauczyciel (kierownik szkoły), który był równocześnie organistą i kościelnym (zakrystianem). Wiadomo, że w I poł. XVII w. w Nowym Waliszowie przy kościele działała szkoła parafialna ${ }^{26}$. $Z$ całą pewnością nauczano w niej śpiewu kościelnego. Z kolei z 1840 r. pochodzi wzmianka o nauczycielu Kreutzerze, który rozpoczął prowadzenie kroniki wiejskiej i kroniki szkolnej ${ }^{27}$. Długoletnim głównym nauczycielem, co najmniej od 1907 do 1933 r., był August Vogel ${ }^{28}$. Prowadził on także Męskie Stowarzyszenie Śpiewacze. W wydanym w 1939 r. schematyzmie diecezjalnym jako chórmistrz wymieniony jest już główny nauczyciel Alfons Fritsch ${ }^{29}$.

Pierwszoplanowym zadaniem chóru parafialnego było uświetnianie liturgii. Nie posiadamy, niestety, zbyt wielu przekazów dotyczących wykonywanego repertuaru. Obok cytowanych już relacji związanych z organami, nieco informacji na ten temat przynoszą sprawozdania prasowe z różnego rodzaju obchodów kościelnych. Pierwsza taka wzmianka pochodzi z 1907 r. i dotyczy uroczystości odpustowej ku czci św. Mikołaja, która odbyła się w niedzielę 8 grudnia ${ }^{30}$. Zabrzmiała wówczas jedna z mszy Josefa Bartscha.

Kolejna relacja z odpustu pochodzi z 1909 r. ${ }^{31}$ Chór parafialny w pełnej obsadzie wykonał Missa in F-dur op. 122 (Hedwigsmesse) - najnowsze dzieło wrocławskiego kapelmistrza katedralnego Maxa Filkego. Ponadto zabrzmiały: ofertorium Veritas mea Rudolfa Bibla i Tantum ergo Heinricha Götzego.

${ }^{24}$ A. Prasal, Z dziejów cecylianizmu w hrabstwie kłodzkim, „Zeszyty Muzeum Ziemi Kłodzkiej” 2011, nr 11, s. 73.

${ }^{25}$ ADGl, sygn. V A 34i: Pfarrei Neuwaltersdorf 1795-.

${ }^{26}$ Stownik Geografii, s. 310.

${ }^{27}$ A. Fritsch, Geschichte der Kirche zu Neuwaltersdorf. Aus älterer Zeit, s. 681.

${ }^{28}$ GB 1907, nr 100; „Grafschafter Volkskalender” 1933, nr 10, s. 41.

${ }^{29}$ Verzeichnis der Pfarreien, s. 37.

${ }^{30}$ GB 1907, nr 100.

${ }^{31}$ GB 1909, nr 100. 
W 1911 r. podczas uroczystości tytułu kościoła wykonano Missa solemnis in $D$ (Oriens ex alto) op. 106 Maxa Filkego, ofertorium Veritas mea Rudolfa Bibla i Tantum ergo J. Bartscha ${ }^{32}$. Na wejście i komunię zaśpiewano utwory chorałowe z Graduale Romanum.

Kolejna relacja pochodzi dopiero z 1927 r. i dotyczy bardzo uroczyście celebrowanego w Nowym Waliszowie wspomnienia św. Anny ${ }^{33}$. Chór wykonał Missa in hon. B. M. Virginis in F op. 160 Paula Mittmanna, graduał Josefa Linnera, ofertorium Josepha Grubera oraz ośmiogłosowe Tantum ergo Vinzenza Gollera. Z kolei podczas święta Matki Bożej Różańcowej w tym samym roku zaprezentowano Missa in G op. 140 Paula Mittmanna, graduał Fiesela (?) oraz ofertorium Josepha Grubera ${ }^{34}$.

Rocznicę poświęcenia kościoła w 1928 r. obchodzono w niedzielę 16 września ${ }^{35}$. Chór parafialny wykonał wówczas po raz kolejny Missa in hon. B. M. Virginis in F, op. 160 Paula Mittmanna.

5 maja 1931 r. parafia przeżywała obrzęd instalacji nowego proboszcza ks. Georga Charfreitaga $^{36}$. Uroczystościom przewodniczył wielki dziekan Franz Dittert. Wprowadzeniu nowego duszpasterza w progi kościoła towarzyszyła pieśn Heil der Demut. Po dojściu do ołtarza zaintonowano hymn Veni creator spiritus. Podczas uroczystej Mszy św. z lewitami chór parafialny wykonał Missa Mater admirabilis op. 86 Petera Griesbachera. Nabożeństwo zakończyło odśpiewanie hymnu Te Deum laudamus.

Znany jest jeszcze repertuar uroczystości pierwszokomunijnej w $1931 \mathrm{r} .{ }^{37}$ Procesyjnemu przejściu 49 dzieci ze szkoły do kościoła towarzyszył śpiew przy akompaniamencie orkiestry. W czasie Eucharystii zabrzmiała Missa in G op. 140 Paula Mittmanna, a na komunię pieśń $O$, mein Jesu, komm 'zu mir.

Kolejnym przejawem działalności chóru kościelnego było organizowanie koncertów wokalno-instrumentalnych. Znane są programy trzech takich imprez. Wszystkie miały miejsce w dysponującej dużą salą gospodzie Carla Rupprechta. Pierwszy koncert, przy dużym udziale publiczności, odbył się w uroczystość Wniebowstąpienia Pańskiego 1905 r. ${ }^{38} \mathrm{Na}$ początku wysłuchano następujących utworów: marsza na orkiestrę Grüß Gott, Wien! Karela Komzáka; Das Grab im Busento Arthura Rosenstengela na chór męski z towarzyszeniem fortepianu; Mein Herz tu' dich auf Franza Wilhelma Abta na sopran i męski kwartet wokalny; Dir gilt mein

\footnotetext{
${ }^{32}$ GB 1911, nr 100.

${ }^{33}$ GB 1927, nr 175.

${ }^{34}$ Tamże, $\mathrm{nr} 232$.

${ }^{35}$ GB 1928, nr 260.

${ }^{36}$ „Grenzblatt für den Kreis Habelschwerdt” 1931, nr 57.

${ }^{37}$ Tamże, nr 59.

${ }^{38}$ GB 1905, nr 46-47; GZ 1905, nr 45.
} 
letztes Grüßen oraz Sehnsucht nach dem Frühlinge Paula Mittmanna na sopran, skrzypce i fortepian; Still wie die Nacht, tief wie das Meer Karla Götzego na tenor i bas; Das einsame Röslein im Tal Eduarda Hermesa na chór męski; Zu Straßburg auf der langen Brück w opracowaniu Carla Hirscha na chór męski; Im Dunkeln E.S. Engelsberga (Eduarda Schöna) na chór męski z towarzyszeniem fortepianu; gawotu Mein Herzblatt Scheunerta na orkiestrę oraz walca Wiener Bürger Carla Michaela Ziehrera na orkiestrę. W części drugiej wystawiono dwuaktową farsę Eine Treppe höher, oder: Auf falscher Fährte Otto Trendiesa. Występy zakończyła potańcówka. Dochód z imprezy w wysokości 75,35 marek został przeznaczony na potrzeby parafii i szkoły.

Kolejny koncert, pod kierunkiem głównego nauczyciela Vogela, odbył się 8 grudnia 1907 r. Wiadomo jedynie, że duży aplauz zyskały humorystyczne występy trzech chórzystów o nazwiskach: Zonzalla, Fischer i Simon ${ }^{39}$.

Trzeci koncert miał miejsce 27 listopada 1929 r. Chór kościelny wraz ze stowarzyszeniem śpiewaczym uczciły wówczas wspomnienie św. Cecyliii ${ }^{40}$. W pierwszej części występu wysłuchano m.in. Herbstnacht Maxa von Weinzierla na chór mieszany oraz cyklu An der Wolga Hugo Jüngsta na chór męski z towarzyszeniem fortepianu i kwintetu smyczkowego. Partie solowe zaśpiewał nauczyciel Krause. W części instrumentalnej 22-osobowa orkiestra wykonała m.in. marsz Mein Regiment Hermanna Ludwiga Blankenburgera oraz uwerturę do operetki Banditenstreiche Franza von Suppégo. Na część trzecią złożyły się dwie pogodne śpiewogry Maxa Legova: Der gepfändete Freier i Der streikende Tenor. Cäcilienfeier zakończyła potańcówka.

Członkostwo w chórze kościelnym nie tylko dawało możliwość realizacji muzycznych pasji, ale stanowiło również sposób spędzania wolnego czasu w „rodzinnej” atmosferze. Wiadomo, że 26 lipca 1927 r. w gospodzie Becka odbyło się spotkanie chórzystów z Nowego i Starego Waliszowa połączone ze wspólnym śpiewem i tańcami ${ }^{41}$.

\section{INWENTARZ MUZYKALIÓW Z 1939 ROKU}

Cennych informacji o wykonywanym przez chór repertuarze może dostarczyć wspomniany już inwentarz parafialny z 1939 r. Zawiera on liczący aż 233 pozycji wykaz muzykaliów będących na wyposażeniu miejscowego kościoła ${ }^{42}$.

\footnotetext{
${ }^{39}$ GB 1907, nr 100 .

${ }^{40}$ GB 1929, nr 330.

${ }^{41}$ GB 1927, nr 175.

${ }^{42}$ Zob. ADGl, sygn. V A 34i: Pfarrei Neuwaltersdorf.
} 
Waliszowski zespół dysponował 69 mszami, w tym 12 za zmarłych. Największą popularnością cieszyły się dzieła krosnowickiego kantora Ignaza Reimanna (18201885) oraz cecylianisty Josepha Grubera (1855-1933). W inwentarzu znajdowały się także utwory innych rodzimych twórców: związanego z Mostowicami Josefa Güttlera (1841-1912) czy pochodzącego z Bystrzycy Kłodzkiej Paula Mittmanna (1868-1920). Z kolei twórczość śląskich kompozytorów reprezentowały dzieła kapelmistrzów katedry wrocławskiej: Moritza Brosiga (1815-1887) i Maxa Filkego (1855-1911). W wykazie zabrakło dzieł muzyki dawnej. Fakt ten nie dziwi o tyle, że tego typu utwory wykonywane były na terenie hrabstwa kłodzkiego tylko przez lepsze zespoły ${ }^{43}$.

Poza cyklami mszalnymi waliszowski zespól dysponował jeszcze: 28 zbiorami graduałów, 21 zbiorami ofertoriów, 15 zbiorami hymnów oraz 14 litaniami. Obok wspomnianych już kompozytorów (zwłaszcza Josepha Grubera i Ignaza Reimanna), przeważały tu dzieła popularnych w hrabstwie kłodzkim twórców (m.in. Rudolfa Bibla czy Aloisa Edenhofera). Pojawiają się także kompozycje innych rodzimych artystów: noworudzkiego chórmistrza Paula Elsnera (1865-1933), wspomnianego już Josefa Linnera (1872-1915) oraz pochodzącego z Krosnowic Franza Reimanna (18551926?) - chórmistrza i nauczyciela w Świdnicy. Ten ostatni był autorem m.in. Stacji na Boże Ciało. Dużą grupę muzykaliów stanowiły także różnego rodzaju opracowania chóralne pieśni kościelnych, zwłaszcza maryjnych (w tym antyfon) i pogrzebowych.

W Nowym Waliszowie praktykowano także wspólny śpiew niemieckojęzycznych pieśni kościelnych, o czym świadczy obecność dziesięciu egzemplarzy Gesang- und Gebetbücher oraz sześciu egzemplarzy Kirchengesangbücher. Swoje skromne miejsce w repertuarze miejscowego chóru znalazł też chorał gregoriański. W spisie muzykaliów odnajdujemy bowiem Großes Gradualbuch oraz cztery egzemplarze Kyriale. Wydaje się jednak, że - podobnie jak w pozostałych wiejskich parafiach kotliny kłodzkiej - chorał wykonywany był sporadycznie ${ }^{44}$. Zadziwia natomiast brak utworów organowych, poza dwoma wydaniami chorału opracowanego przez Wilhelma Kothego (1831-1899) - wykładowcy muzyki w seminarium nauczycielskim w Bystrzycy Kłodzkiej.

\section{PODSUMOWANIE}

Świątynia pw. św. Mikołaja przez stulecia była głównym miejscem uprawiania i rozwijania sztuki muzycznej w Nowym Waliszowie. Już w 1699 r. wyposażono ją

\footnotetext{
${ }^{43}$ A. Prasal, $Z$ dziejów cecylianizmu, s. 75.

${ }^{44}$ Tamże.
} 
w 7-głosowy pozytyw. Niewielka parafia dysponowała także zespołem wokalno-instrumentalnym, który nie tylko dbał o liturgię, ale także organizował koncerty. Chór prowadzili miejscowi nauczyciele, którzy byli jednocześnie organistami. Cennych informacji o repertuarze zespołu dostarcza inwentarz muzykaliów z 1939 r. Kolekcja ta świadczy o dość przyzwoitym poziomie kultury muzycznej w Nowym Waliszowie. Na jej podstawie można stwierdzić, że zarówno pod względem doboru utworów, jak i wykonawstwa repertuar ten nie tylko dorównywał, ale niejednokrotnie przewyższał praktykę muzyczną innych wiejskich świątyń ziemi kłodzkiej. Na uwagę zasługuje wykonywanie utworów rodzimych kompozytorów, wywodzących się z terenu hrabstwa kłodzkiego (Paula Elsnera, Josefa Güttlera, Josefa Linnera, Paula Mittmanna, Ignaza Reimanna, Franza Reimanna). Znamienne jest, że tak różnorodny i w miarę ambitny repertuar znalazł swoje miejsce w niewielkiej parafii. Niestety, brak dostatecznej liczby przekazów źródłowych pozostawia bez odpowiedzi pytanie, na ile zawarte $w$ inwentarzu utwory znalazły swoje odzwierciedlenie w praktyce wykonawczej waliszowskiego chóru.

\section{BIBLIOGRAFIA}

Archiwum Parafii Rzymskokatolickiej pw. Wniebowzięcia NMP w Kłodzku, Das Dekanatsarchiv des Erzbischöflichen Generalvikariats der Grafschaft Glatz:

- b. sygn.: Orgel-Meldebogen 1943-1945.

- sygn. V A 34i: Pfarrei Neuwaltersdorf 1795-.

Archiwum Wojewódzkiego Urzędu Ochrony Zabytków we Wrocławiu. Delegatura w Wałbrzychu, Karta ewidencyjna organów w kościele filialnym pw. św. Mikołaja w Nowym Waliszowie (opr. T. Grabska, J. Stępowski, 1993 r.).

FrITSCH A., Geschichte der Kirche zu Neuwaltersdorf. Aus älterer Zeit, „Arnestus-Blatt” 1937, nr 48, s. 681-682. Fritsch A., Geschichte der Kirche zu Neuwaltersdorf. Aus jüngerer Zeit, „Arnestus-Blatt” 1937, nr 50, s. $710-711$.

Fritsch A., Geschichte der Kirche zu Neuwaltersdorf. Aus der letzten Jahrhundert, „Arnestus-Blatt” 1937 , nr 51, s. 724.

„Der Gebirgsbote” 1904-1929.

„Glatzer Zeitung” 1902-1912.

„Grafschafter Volkskalender” 1933, nr 10.

„Grenzblatt für den Kreis Habelschwerdt” 1931.

Kögler J., Die Chroniken der Grafschaft Glatz, t. 4: Die Chroniken der Dörfer, Pfarreien und Herrschaften des Kreises Habelschwerdt, opr. D. Pohl, Dr. Dieter Pohl Verlag, Köln 2001.

Pismo firmy Berschdorf z Nysy do Katolickiego Zarządu Kościelnego w Nowym Waliszowie z 27 maja $1939 r$. (zbiory własne).

Pismo firmy Berschdorf z Nysy do Katolickiego Zarządu Kościelnego w Nowym Waliszowie z 7 lipca $1942 r$. (zbiory własne).

Prasal A., Organy w kościołach dekanatu Bystrzyca Kłodzka, Polihymnia, Lublin 2013.

Prasal A., Z dziejów cecylianizmu w hrabstwie kłodzkim, „Zeszyty Muzeum Ziemi Kłodzkiej” 2011, nr 11, s. 65-90. 
Staffa M. (red), Stownik Geografii Turystycznej Sudetów, t. 15: Kotlina Kłodzka, Wydawnictwo I-BIS, Wrocław 1994.

Verzeichnis der Pfarreien, Kuratien, Geistlichen und Ordensniederlassungen in der Grafschaft Glatz, dem preuß. Anteil der Erzdiözese Prag, Arnestus-Druckerei, Glatz 1939.

„Zeitschrift für Instrumentenbau” 1912, nr 33.

\title{
Z DZIEJÓW MUZYKI W KOŚCIELE PW. ŚW. MIKOŁAJA W NOWYM WALISZOWIE NA ZIEMI KŁODZKIEJ
}

\author{
Streszczenie
}

Początki kultury muzycznej Nowego Waliszowa związane są z tamtejszą świątynią pw. św. Mikołaja. Już w 1699 r. wyposażono ją w 7-głosowy pozytyw. Obecne organy zostały wybudowane w $1912 \mathrm{r}$. przez firmę Schlag \& Söhne ze Świdnicy. Instrument typu multiplex o pneumatycznej trakturze rejestrów i gry posiada 15 głosów, w tym dziewięć realnych. Niewielka parafia dysponowała także zespołem wokalno-instrumentalnym, który nie tylko dbał o liturgię, ale także organizował koncerty. W $1930 \mathrm{r}$. liczył 31 chórzystów i 16 instrumentalistów. Zespół prowadzili miejscowi nauczyciele, którzy byli jednocześnie organistami. Cennych informacji o repertuarze chóru dostarcza inwentarz muzykaliów z 1939 r. obejmujący m.in.: 69 mszy, 28 zbiorów graduałów, 21 zbiorów ofertoriów, 15 zbiorów hymnów, 14 litanii oraz dużą liczbę pieśni kościelnych. Na jego podstawie można stwierdzić, że zarówno pod względem doboru utworów, jak i wykonawstwa repertuar ten nie tylko dorównywał, ale niejednokrotnie przewyższał praktykę muzyczną innych wiejskich świątyń ziemi kłodzkiej.

Słowa kluczowe: Nowy Waliszów; muzyka kościelna; chór parafialny; organy; inwentarz muzykaliów.

\section{FROM THE HISTORY OF ST. NICHOLAS' CHURCH IN NOWY WALISZÓW IN KŁODZKO COUNTY}

\section{Sum mary}

The beginnings of musical culture in Nowy Waliszów are connected with the local St. Nicholas' church. As early as 1699 it was equipped with a seven-piped positive organ. The present organ was built in 1912 by the company Schlag \& Söhne from Świdnica. The instrument is a multiplex organ with pneumatic register and key action, with 15 stops including nine real stops. The small parish had a vocal and instrumental ensemble which not only enriched the liturgy, but also organized concerts. In 1930 it counted 31 choristers and 16 instrumentalists. The ensemble was conducted by the local teachers, who at the same time worked as organists at the local church. The 1939 musical inventory provides valuable information about the choir's repertoire, which includes, among others, 69 masses, 28 collections of graduals, 21 collections of offertories, 15 collections of hymns, 14 litanies as well as a considerable number of church songs. Judging by this inventory it can be established that with regard to the choice of works as well as to the performance of that repertoire, it not only equals, but frequently exceeds the level of musical practice cultivated in other village churches in Kłodzko County.

Key words: Nowy Waliszów; church music; parish choir; organs; musical inventory. 